\title{
TUMOUR OF THE OPTIC CHIASMA
}

\author{
BY \\ S. N. JAVETT and ERIC SAMUEL \\ Johannesburgh, South Africa
}

Tumours arising in the small area at the base of the brain between the optic chiasma and cerebral peduncles are common and include meningiomas, suprasellar and pituitary neoplasms, aneurysm of the circle of Willis, and chiasmal arachnoiditis with cyst formation. Tumours arising in the optic chiasma and nerve sheaths, however, are very uncommon. In all these conditions, visual symptoms may obtrude to a degree that renders clinical differentiation difficult. In the case of chiasmal glioma here reviewed, diagnosis was much simplified by the characteristic radiological features.

\section{Case Report}

A bright and alert male child aged five and a half years was referred because of defective vision in the right eye. There was nothing relevant in the past history. He was the elder of two children of normal parents. Pregnancy and labour were normal and the birth weight was $6 \mathrm{lb}$. $5 \mathrm{oz}$. He had been artificially fed from birth, he thrived and developed well, and all the milestones were normal. At the age of fifteen months he had a sore throat with an accompanying convulsive episode attributed to high fever. Three months later he contracted measles and again exhibited two tonic convulsions in association with a high temperature. Unconsciousness lasted two minutes on each occasion. These febrile convulsions are in keeping with the cortical dysrhythmia which was found later in the electroencephalogram, and which was presumably of the inherited type as both his father and younger sister had convulsions under similar circumstances. He had remained perfectly well until two and a half months before admission, when he complained of a slight headache, frontal in distribution, worse in the evening and improving in the morning. He had two further headaches of similar nature. The parents consulted an ophthalmologist, who reported that the child was blind in the right eye, the left being normal. The child never complained that he could not see, nor had his school mistress suspected defective vision. There was no nausea, vomiting, polyuria, polydipsia, or loss of weight.

On examination it was found that the child's faculties were normal. He was not ill, nor in any discomfiture. There was no jaundice, cyanosis, dyspnoea, or oedema. Temperature, pulse rate, and respiration, heart, lungs, and abdomen were all normal. Blood pressure was $100 / 60 \mathrm{~mm}$. Hg.
There was no external evidence of neurofibromatosis. The child appeared normally proportionedweight $37 \mathrm{lb}$., height 42 in., span 42 in., symphysis to vertex 22 in., symphysis to ground 20 in., skull circumference 20.5 in. No neck rigidity or murmurs on auscultation of the skull, and no exophthalmos or ptosis were noted. All the cranial nerves except the second appeared normal. Central vision in the right eye was absent, but on confrontation tests movements were perceived in the temporal field. Consensual and light reflexes were present, but the contraction of the right pupil to light was not as full as the left nor as well maintained. The optic disc was white, its edges sharply defined and the vessels normal. Vision in the left eye was full, but the disc was paler than normal, especially of the nasal half. Accurate plotting of the visual fields was impossible because of the child's age. The eye findings were interpreted as a large central scotoma of the right eye with well marked optic atrophy and commencing atrophy of the left disc. The rest of the cranial nerves and central nervous system were normal.

LABORATORY STUDIES. The blood count was : haemoglobin, 13.4 g.; colour index, 0.99; red blood cells, 4,340,000; white blood cells, 7,900 per $100 \mathrm{c} . \mathrm{mm}$. of blood; polymorphs, 51 per cent.; monocytes, 4 per cent.; lymphocytes, 43 per cent.; eosinophils, 2 per cent.

The sedimentation rate was: $15 \mathrm{~mm}$. in the first hour. The blood Wassermann reaction was negative. The specific gravity of the urine was 1024 , and there was no albumin or sugar. The Mantoux (1/1000) test was negative.

The glucose tolerance test was: fasting, $95 \mathrm{mg}$. per cent.; after ingestion of glucose, $70 \mathrm{mg}$., $80 \mathrm{mg}$., $90 \mathrm{mg}$., $50 \mathrm{mg}$. at half-hourly intervals. This represents doubtful increase of tolerance to glucose.

A radiograph of the wrist joint showed a normal ossification index.

Cerebrospinal fluid pressure was $110 \mathrm{~mm}$. with no block (one lymphocyte; no bacteria; protein $70 \mathrm{mg}$. per cent.; chlorides $720 \mathrm{mg}$. per cent. ; sugar $60 \mathrm{mg}$. per cent.; Wassermann reaction negative).

Eight hours after lumbar puncture the child complained of severe pain in the back and right hip which radiated down the back of the right leg. The pain persisted for two days. It then ceased but was replaced by an attack of headache and vomiting which lasted a further three days. The 
post lumbar puncture episode was undoubtedly of some significance even though cerebrospinal fluid pressure was normal.

RADIOGRAPHY OF THE SKULL. The lateral radiograph of the sella turcica and the region of the sulcus chiasmaticus (Plate VIIa) revealed a characteristic enlargement of the anterior part of the sella turcica with an excavation of the under surfaces of both anterior clinoid processes. These changes were caused by a pressure atrophy, and the bone in the affected region was thinned. A lateral tomograph (Plate VIIb) of the sella turcica demonstrated these changes even more clearly.

Rhese Goalwin view (Plates VIIc and d) revealed an increase in the size of both optic foramina, the right more than the left. It is interesting to note that on the left side, the less affected side, the margin of the optic foramen was sclerosed, suggesting that in the early stages irritation may lead to sclerosis whilst later pressure causes atrophy of the foraminal margin.

An electroencephalogram with monopolar leads from both hemispheres showed rather erratic recordings. Mixed frequencies of 1-10 per second were present. It was concluded that there was cortical dysrhythmia without focalization; there was no evidence of epilepsy.

Consideration of the clinical findings pointed to a space-occupying lesion in the region of the pituitary fossa. The radiographs more accurately localized the lesion to the region of the sulcus chiasmaticus of the sphenoid bone and demonstrated that the floor and the posterior clinoid processes of the sella turcica were intact. In addition, there was enlargement of both optic foramina, indicating that both optic nerves were involved. A diagnosis of chiasmal glioma was made and an exploratory operation was advised to verify the diagnosis. Prefrontal craniotomy was undertaken by Dr. R. Krynauw, who reported: "After the optic nerve had been stripped, a large pink tumefaction about the size of a pigeon's egg was encountered. It was continuous with the chiasma and extended backwards along the optic tracts. Removal of this lesion would be technically impossible or nearly so.' Three months after the operation the general condition of the child was unchanged. The right eye was totally blind.

\section{Comment}

Chiasmal glioma is essentially a condition of childhood. It arises in the chiasma or adjacent wall of the third ventricle, spreading forwards to involve the nerve even as far as the papilla. Intracranial involvement of the optic nerve is much rarer than intraorbital involvement. The growth is slow and may not cause death for many years. Davis (1940), reviewing the literature since 1876 , found thirty-eight cases associated with neurofibromatosis, in twelve of which there was an hereditary element. Vision is involved early, and marked deterioration or even blindness may be present before symptoms of cranial hypertension manifest themselves. Visual affect is bizarre, optic atrophy and central scotoma tending to appear rather than bi-temporal or homonymous hemianopia. Where the nerve head has been invaded, exophthalmos may be present. In many of the reported cases endocrine symptoms have been absent, though Ford states that polydipsia, polyuria and obesity, consequent on pressure on the hypothalamus, are common. The radiograph shows a bulging or erosion beneath the anterior clinoids; enlargement of the optic foramina can often be observed.

Differential diagnosis. Other conditions involving the optic chiasma require consideration in the diagnosis, namely craniopharyngioma, pituitary tumour, aneurysm of the circle of Willis, suprasellar meningioma, and chiasmal arachnoiditis with cyst formation.

Craniopharyngioma. This is a not infrequent tumour of childhood, constituting roughly oneseventh of all intracranial neoplasms at this age, and is the most important condition requiring differentiation. The subject has been well reviewed by Ingraham and Scott (1946), who point out that, in contradistinction to chiasmal glioma, signs of intracranial hypertension such as headache and vomiting precede visual disturbance. The latter takes the form of lower quadrantic defects proceeding to bi-temporal hemianopia. Optic atrophy may occur. Evidence of acute hydrocephalus can be established by ventriculography. Pressure on the hypophysis commonly leads to arrested skeletal development, whilst hypothalamic signs are rare. In the radiograph suprasellar or intrasellar calcification is present in 75 per cent. of cases. Separation of sutures, convolutional atrophy, erosion of posterior clinoids, enlargement and distortion of the floor of the sella may also be noted in the radiograph. Pressure atrophy of the anterior clinoid processes is seldom marked, and when marked generally involves the superior surface of the anterior clinoid process in contradistinction to the chiasmal glioma (Plate VIIe).

PITUITARY NEOPLASM. The age factor operates heavily against a diagnosis of pituitary neoplasm, which is practically unknown under the age of ten years. Here, endocrine disturbance is to the forefront. Reference has already been made to the radiological location of the maximal pressure changes in chiasmal glioma as affecting the anterior part of the sella turcica with little involvement of the floor or post-clinoid processes. A pituitary tumour throws the main stress of pressure atrophy on the floor and post-clinoid process (Plate VIIf). A radiological appearance of an eroded anterior clinoid process without involvement of the floor or post-clinoid process is against the diagnosis of a primary pituitary neoplasm.

Meningioma. The age factor applies similarly to meningioma, commonly seen in middle-aged adults. Meningioma arising near the body and lesser wing of the sphenoid generally produces some 
sclerosis of the adjoining bone, and atrophy is less common.

ANEURYSM. This, too is not common in children. Associated palsies of third, fourth, and sixth cranial nerves may be present in addition to the chiasmal syndrome. Calcification may be detected by radiograph in the wall of the aneurysm, and the clinoids may show localized erosion. Angiography is conclusive.

ARACHNOIDITIS. This is usually the sequal of trauma and is unaccompanied by endocrine disturbance. Plain radiography is negative but encephalographic studies have shown characteristic appearances.

\section{Summary}

A case of chiasmal glioma is described and the clinical and radiological features discussed. A chiasmal syndrome in the first decade of life, with the radiological features of enlargement of both optic foramina, erosion beneath the anterior clinoid processes, and enlargement of the sulcus chiasmaticus is almost diagnostic of this condition.

\section{REFERENCES}

Davis, F. A. (1940). Arch. Ophthal. N.Y., 23 (N.S.), 735 and 957.

Ford, F. R. (1945). Disease of Nervous System in Infancy, Childhood and Adolescence. 2nd Edition, p. 803. Springfield, Illinois.

Ingraham, F. D. and Scott, H. W. (1946). J. Pediat., 29, 95.

Pendergrass, E. P. and Perryman, C. R. (1946). Amer. J. Roentgen., 56, 279.

(For illustrations to this article see Plate VII, p. 259.) 


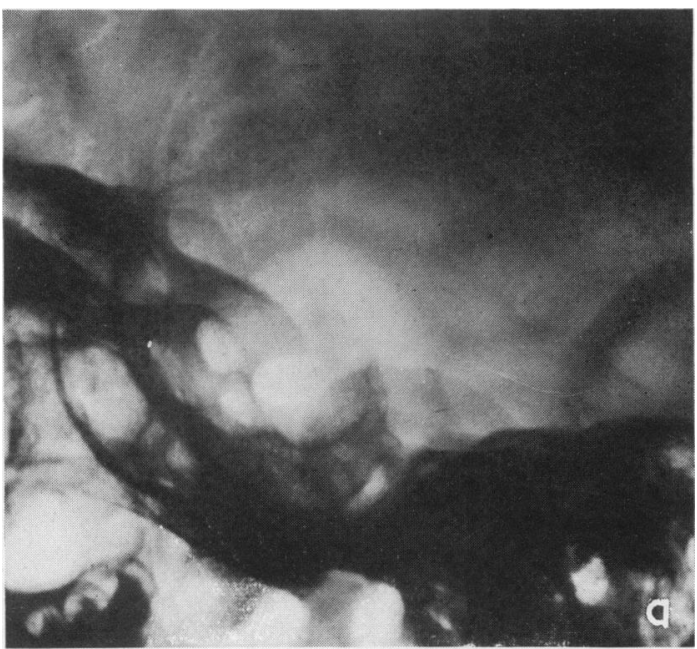

(a)-Lateral localized view of sella turcica; shows excavation beneath anterior clinoid processes and pressure atrophy of floor of sulcus chiasmaticus. The sella turcica behind this area is unaffected.

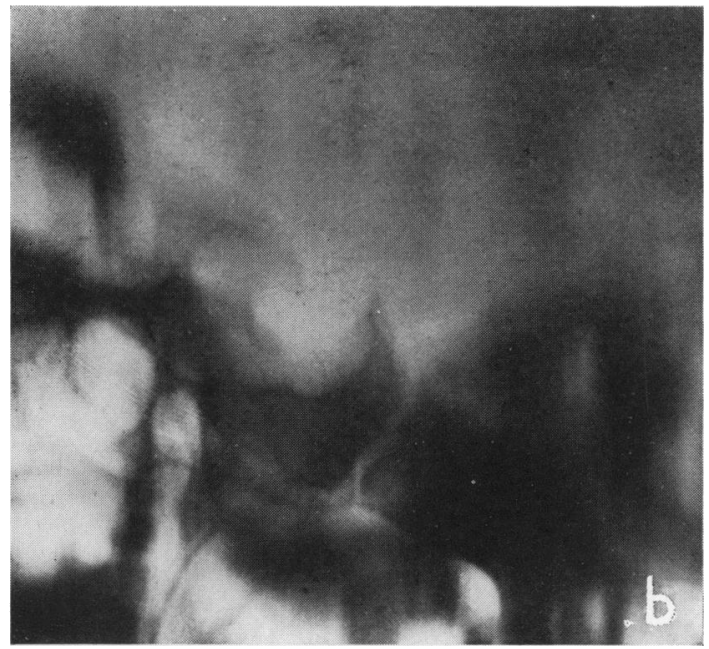

(b)-Tomographic film taken at 5 c.m. in the lateral position. The changes in the bony walls of the sulcus chiasmaticus can be clearly seen.
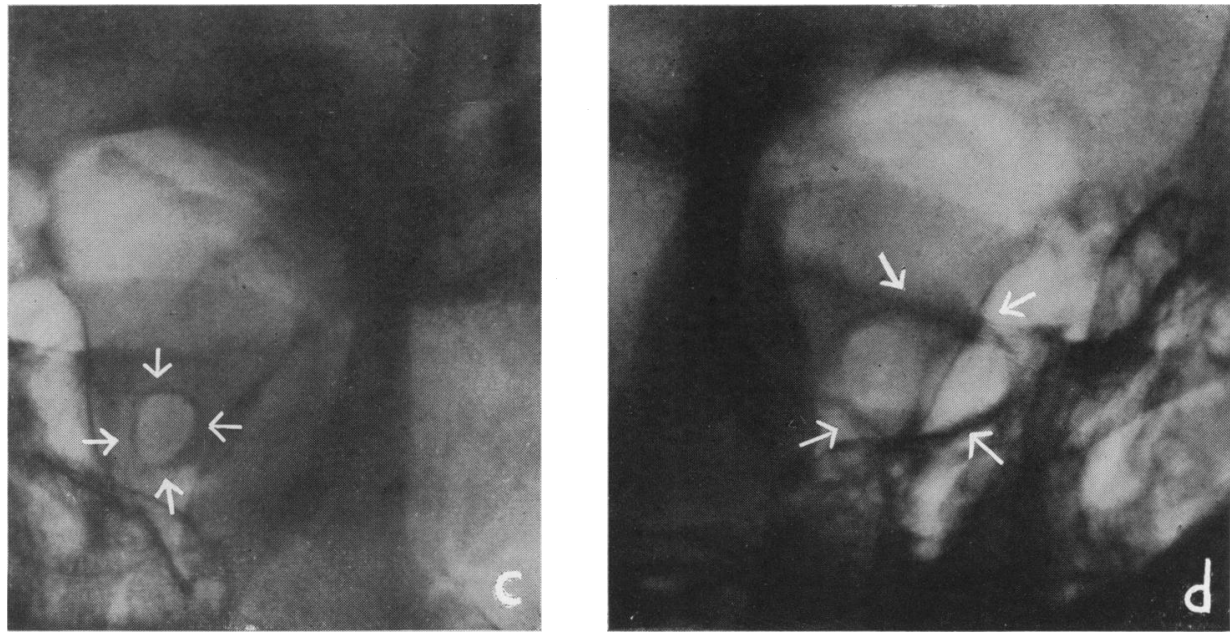

Rhese Goalwin view of (c) left optic foramen, to demonstrate enlargement of optic foramen ; and (d) right optic foramen, to show massive enlargement of that structure with thinning of surrounding bony wall.

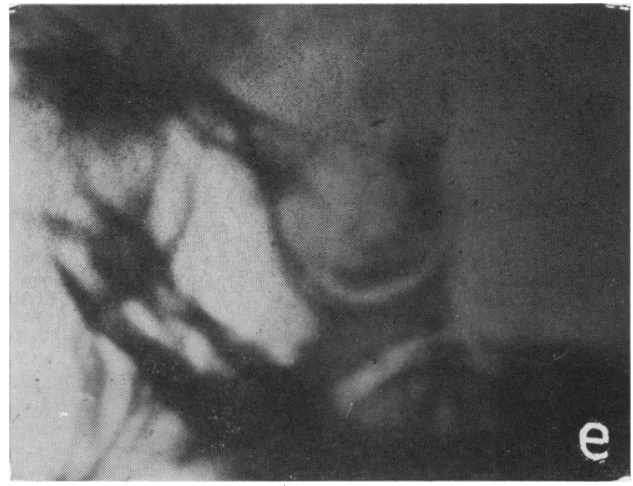

(e)-Lateral radiograph in a case of craniopharyngioma, for comparison. Note erosion of upper surface of anterior clinoid processes, and the calcification.

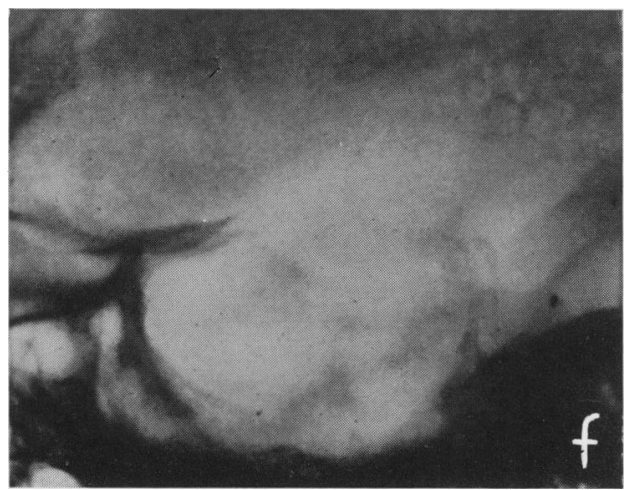

(f) - Lateral radiograph from a case of a chromaphobe adenoma of the pituitary. Note generalized enlargement of pituitary fossa, and especially the manner in which the main stress falls on the posterior clinoid processes. 